Copyright $\circledast$ Manchester University Press 2016

While copyright in the volume as a whole is vested in Manchester University Press, copyright in individual chapters belongs to their respective authors, and no chapter may be reproduced wholly or in part without the express permission in writing of both author and publisher.

Published by Manchester University Press

Altrincham Street, Manchester M1 7JA

www.manchesteruniversitypress.co.uk

British Library Cataloguing-in-Publication Data

A catalogue record for this book is available from the British Library

Library of Congress Cataloging-in-Publication Data applied for

ISBN 9780719097171 hardback

First published 2016

The publisher has no responsibility for the persistence or accuracy of URIs for any external or third-party internet websites referred to in this book, and does not guarantee that any content on such websites is, or will remain, accurate or appropriate.

Typeset

by JCS Publishing Services Ltd 


\section{Ostentatiously discreet: bisexual camp in The Stranger's Child}

Joseph Ronan

Alan Hollinghurst has suggested that there is 'a lot in The Stranger's Child which is rather liminal ... there's quite a lot of bisexuality'. ${ }^{1}$ Despite this, the words bisexual or bisexuality appear exactly never in the novel's 564 pages. A number of characters display what we might reasonably consider bisexual behaviour yet bisexuality in this novel is unnamed, perhaps unnameable. Similarly, many responses to the novel, even those which do describe some characters as bisexual, have tended to position its explorations of history, memory and literary tradition in relation to homosexuality or gayness. Such readings mistake the activities of the characters within the text for the activity of the text itself. They erase the significant amounts of bisexual behaviour in evidence throughout it and situate the novel in precisely the gay context which, I argue, it undermines.

Rewritten as gay, queer or an immature, transitional identity, the text's unnameable bisexuality speaks to a contemporary moment in which bisexuality largely remains culturally illegible, subsumed under different narratives. This essay advances a reading of The Stranger's Child that puts its bisexualities in dialogue with its campness to reveal the novel's interactions with the mainstreaming of gay culture, the advance of queer theory, and what Kenji Yoshino describes as the 'epistemic contract of bisexual erasure' between gay and straight discourses that ensure that bisexuality remains invisible. ${ }^{2}$ I argue that The Stranger's Child takes the cultural illegibility of bisexuality and runs with it, making an outrageous camp excess out of its absence, and structuring its narrative through the supposed irresolvabilty of bisexuality as an identity position.

Robyn Ochs notes that due to a lack of bisexual visibility outside a limited set of behaviours (such as having simultaneous partners of different genders), 'many people equate 
bisexuals with promiscuity ..., untrustworthiness, horniness and hypersexuality. Bisexuals who are not currently engaging in one of these behaviors are seen as ("well-behaved") straight, lesbian or gay people'. ${ }^{3}$ Phoebe Davidson also shows that a linear sexual narrative bolsters a perception of bisexuality as immature. Since 'sexuality is perceived as a maturation process ... bisexuality could be perceived at the beginning, in infancy, but it certainly has no place at the end of this process, in adulthood'. ${ }^{4}$ As Marjorie Garber states, this narrative is based on "the idea that it is "normal" to reach a settled sexual identity, and that that "identity" is either heterosexual or homosexual'. ${ }^{5}$ Moreover, Esther Saxey's analysis of the mechanics of the gay coming-out narrative reveals that it typically 'uses the exclusion of any bisexual potential as one of its key [. . . incidents', ${ }^{6}$ an exclusion which 'becomes the climax of an ethical battle between enforced, inauthentic heterosexuality and redemptive gay honesty'? Elsewhere she explains that 'the key cultural story we have for understanding same-sex sexual desire' has therefore 'excluded the possibility of a character with self-aware, ongoing desire for both sexes', and has therefore cast bisexuality as an unresolved, transitory position en route to a fixed and authentic monosexual identity. ${ }^{8}$ In addition, Clare Hemmings notes that some queer theorists refuse 'to recognize bisexuality as a valid and enduring sexual identity and bisexuals themselves as authentic subjects'. ${ }^{9}$ This can lead to subsumption into a queer discourse which is supposedly inclusive but, as David Halperin has noted, in practice has often 'subsided into a mere synonym of gay', effacing specifically bisexual experiences and perspectives. ${ }^{10}$

The Stranger's Child rehearses all of these positions although not as a further unfortunate act of bisexual erasure. Rather, this essay reads the novel as a camp critique of the personal and cultural narrative processes that lead to such erasure in the first place. Georges Letissier notes "the potentialities of "camp" as a countercultural impulse within Alan Hollinghurst's aesthetic' more generally; ${ }^{11}$ I posit this camp impulse in The Stranger's Child 
as a specifically bisexual one, countering the culture of erasure fostered by straight, gay and contemporary queer discourses. 'Trying to define Camp is like attempting to sit in the corner of a circular room', as Andy Medhurst memorably observes. 'It can't be done, which only adds to the quixotic appeal of the attempt' ${ }^{12}$ That said, 'most of us know it when we see, hear, feel or do it'. ${ }^{13}$ For Medhurst,

Camp is a set of attitudes, a gallery of snapshots, an inventory of postures, a modus vivendi, a shop-full of frocks, an arch of eyebrows, a great big pink butterfly that just won't be pinned down. Camp is primarily an adjective, occasionally a verb, but never anything as prosaic, as earth-bound, as a noun. ${ }^{14}$

While remaining difficult to define, camp is traditionally understood to have specific historical connections to (primarily male) homosexuality. ${ }^{15}$ This is not to say that that bisexuals do not already do camp, or have not been part of this history, but rather that camp is primarily understood through its relation to homosexuality rather than to bisexuality - which may be in part because bisexuality has been consistently rewritten as gay. Fabio Cleto agrees that many

questions remain to some extent unsettled: about how camp might be defined and historicised, about its relation - be it ontological or happenstantial - to homosexuality (is it an exclusively gay cultural mode of representation, or what? If so, how subversive is it and how much does it comply, or has it historically complied, with the compulsory heterosexual, and both gyno- and homophobic, dominant structures of interpellation?), where and in what forms it can be traced, and about its relation to postmodern epistemology and theories of textuality/ subjectivity. ${ }^{16}$ 
These questions are particularly pertinent to bisexuality, which has an equally uncertain relationship to straight, lesbian and gay identities and to queer theory. A camp which 'hasn't lost its relentless power to frustrate all efforts to pinpoint it down to stability ${ }^{17}$ aligns with bisexuality's 'unresolved definitional uncertainty [which] points to a larger uncertainty about what sexuality is and how it should be understood' ${ }^{18}$

While many characters in The Stranger's Child exhibit bisexualities, my focus is on Cecil Valance, the young aristocratic poet who, in the first section, comes to visit his secret lover George and his family. During this visit he writes a poem, 'Two Acres', which later becomes well-known and is said to have 'entered the language' of the nation (SC 172). 'Two Acres' is ostensibly written for George's younger sister Daphne (with whom Cecil later has a sexual relationship) although there are also unpublished sections written for George that are rediscovered after Cecil's death. Over the course of the novel's five sections (which span 1914-2008 with significant gaps in time between them) characters try and fail to piece together various truths about the poem and the past: a process that involves their writing about Cecil. Among the texts published are: Daphne's memoir detailing her relationship with Cecil; gay writer Paul Bryant's scandalous biography outing Cecil as gay; and queer theorist Nigel Dupont's edited edition of Cecil's poetry in which the previously lost 'queer' verses are made public.

As characters write about Cecil they also rewrite Cecil and his bisexuality as immature, gay or queer. As such, they are shown to be agents of gay/queer and heteronormative practices which overwrite bisexuality. By the end of The Stranger's Child, Cecil stands in for the bisexuality rewritten as gay, the bisexuality subsumed by queer theory, and the bisexuality invalidated as an immature phase en route to a normative straight life marked by marriage and children. What his bisexuality is not allowed to be is the bisexuality that is named, and names itself bisexuality. Attempts by various characters to rewrite Cecil in 
these ways expose what Daniel Mendelsohn identifies in the novel as an 'exploration of the way in which the stories we tell ourselves can occlude (comically or tragically) the real story - how "our" truth ends up obscuring "the" truth, whether in poetry, history or biography". ${ }^{19}$ So, despite Cecil's agency in the brief period he is alive, the rest of the text concerns characters training their various other lenses on him, repurposing his bisexuality and writing monosexual maturity or queer radicality on top of it.

Cecil functions fundamentally as a threshold - as the adolescent bisexuality out of which people, gay or straight, must mature in order to (attempt to) achieve adulthood. The normative straight story, the gay story and the queer story are all imposed on his bisexuality. For Daphne, ostensibly the straight character in the novel, he is no more than a gateway to monosexual maturity.

'Really Cecil means nothing to me -- I was potty about him for five minutes sixty years ago. The significant thing about Cecil, as far as I'm concerned,' said Daphne, half-hearing herself go on, 'is that he led to [first husband] Dud, and the children, and all the grown-up part of my life, which naturally he had no part in himself!' (SC 500)

Well, naturally. How could Cecil, as figure of bisexuality, have any part in the grown-up part of a life when a life can only be read as 'grown-up' by invalidating its bisexuality? In trying to downplay his significance however, she also owns that without him the grown-up part of her life as it is would not have been possible. Bisexuality here is what maturity must reject in order to be read as such, and yet is simultaneously that which brings about that maturity in the first place. Note also the disjuncture between internal and external voices; Daphne only half-hears herself go on. We may assume then that this disavowal is not complete, however much she may outwardly attempt to rewrite Cecil as a fully invalidated immaturity. 
Paul's attempt to re-write Cecil as gay takes a strategic and knowing form. In conversation with a minor character, Jake, Paul explains his project, thus:

'I'm writing a biography of Cecil Valance,' said Paul firmly [. . .]

'So he was gay too was he?'

'Again ... among other things.'

Again Jake was delighted. 'They all were, weren't they?' he said

Paul felt he should be a bit more cautious: 'I mean, he did have affairs with women, but I have the feeling he really preferred boys. That's one of the things I want to find out.' (420)

While acknowledging (but not naming) the bisexual nature of Cecil's actual sexual practices, it is still Paul's feeling that he really preferred boys. There is an ambiguity here as to what, precisely, Paul wants to find out: whether Cecil preferred boys, or that he did? While 'affairs' may be an accurate way to describe Cecil's relations with both men and women, the word's use in connection with only the latter implies a hierarchy in which relations with men are less trivial, more authentic; this is what enables Paul to read Cecil as gay. Marcin Sroczyński rightly notes that

Paul Bryant's quest to prove to the world that Cecil and Dudley Valance were gay receives harsh criticism in the book. The character is denounced at the end of the novel as a rather repellent figure with an ambiguous past [...]. This seems to be Hollinghurst's warning against too fervent a gay activism which may consist in building an artificial 'gay heritage. ${ }^{20}$ 
The warning here is, I think, more specifically against activism that not only finds gayness where it is not, but that actively installs a gay identity at the expense of other, bisexual possibilities.

Paul's work to make Cecil gay directly opposes Nigel Dupont's work to make him queer, which once again lays claim to Cecil at the expense of his bisexuality. While Paul researches Cecil's life for the biography, Dupont prepares his edition of the poems. For Dupont, the 'unpublished part' of 'Two Acres' turned out 'to be a sort of queer manifesto, except in tetrameter couplets' (541), although from what the reader sees of it to 'walk the [. . .] wild dark path of love' (52) hardly seems enough on its own to constitute a queer manifesto. Where Paul has claimed Cecil for gay, on a 'feeling that he preferred boys', Dupont has claimed Cecil for queer with a particular reading of his poem. By the end of the novel, 'the Valance work seemed a distant prolegomenon to far more sensational achievements' (540): namely his 'milestone works in Queer Theory' (528). Cecil, as prolegomenon, provides the introduction to Dupont's later, queerer work.

Underneath the discarded lines of verse on the rediscovered manuscript 'was a very dense crossing out, as if not only Cecil's words but his very ideas had had to be obliterated' (52). We do see the obliteration of Cecil's 'very ideas' in the novel, through their subordination to Paul's 'gay' and Nigel's 'queer.' Cecil obfuscates something in the poem that he considers unnameable and that subsequent readers (must) find illegible. For Paul this is understood as gay, and for Dupont queer: each installs a nameable subject in place of the figurative and literal illegibility and unintelligibility of Cecil's bisexuality. In each of these cases bisexuality is the necessary preface to what becomes differently fixed as straight, gay or queer: the immature gateway to a normative hetero-reproductive future and the prolegomenon to two separate writing careers - the tenacious biographer who outs gays and the successful but pompous queer theorist. Cecil and his bisexuality function as the starting 
point out of which these other identity positionings mature and the 'achievements' of gay and queer writers, presented as a straightforward linear advancement towards commercial success or prestige, rely on the erasure or subsumption of an originary bisexuality.

This rewriting of bisexuality is not confined to the novel; it also characterises many critics' responses to it. For Mendelsohn, for instance, The Stranger's Child is 'about the way in which the true, gay story behind a poem . . . is elided over time'. ${ }^{21}$ James Wood similarly asserts that 'the real subject of Paul's biography, as is the real subject of Hollinghurst's novel, is the hidden homosexuality of [Cecil,] this now idealized literary representative'. ${ }^{22}$ There are a number of problems with situating the text in this way. Firstly it signals and contributes to the erasure of bisexual representation in contemporary culture more generally. Secondly reading the text in terms of a hidden 'true gay story' risks repeating the process through which (particularly male) bisexuals are commonly believed to be 'confused' and 'really gay', ${ }^{23}$ by asserting the authenticity of a gay identity over a transitory bisexual one. But this novel is precisely not about revealing the 'true gay story'. Rather, it demonstrates how the development of that story can impose gayness on other, more ambiguous sexual possibilities. Thirdly, a gay reading of the novel performs the same interpretative mistakes on the novel as its characters do with the poem the within it. Theo Tait describes the novel as a sort of ironic meditation on the evolution of literary memory. It shows how the poem and the original incident behind it are mythologised, and the myth is made official. Later comes the revisionist version ... . The myths are partially corrected, but new myths replace some of the old ones, and new fashions unbalance the historical record just as the old ones did. ${ }^{24}$

Cecil is subject to various mis-readings and re-writings. He functions not only as a fictive origin to which all subsequent sections of the novel return, but also as an elusive and allusive 
stand-in for the 'real' literary past and the processes of re-reading and reinterpretation which literary texts inevitably undergo.

But while the influences of other literary texts are made clear in the abundance of allusion, quotation and quasi-pastiche, The Stranger's Child is as concerned with Hollinghurst's own position in the text as it is with the novel's intertexts. According to one interviewer, Hollinghurst, 'refuses to engage with ... whether he is still pigeonholed as a gay writer'. ${ }^{25}$ 'I spent 20 years politely answering the question, "How do you feel when people categorise you as a gay writer?" and I'm not going to do it this time round. It's no longer relevant', Hollinghurst says. Elsewhere he suggests that he is actually 'not writing such completely gay [novels] anymore, ${ }^{26}$ even though 'there is a particular kind of gay reader who would like me to keep writing the same book over and over again, which I've never had any interest in doing'. ${ }^{27}$ The Stranger's Child, as a not-so-completely-gay text, responds to and rebukes the particular kind of reader Hollinghurst describes here and, more specifically, the novel's bisexualities stage a camp critique of their inevitable (mis)interpretation within the context of the 'gay' novel.

One of the key historical functions of camp has been as a coding practice that communicates queerness to those in the know, while remaining hidden (or at least plausibly deniable) to mainstream culture. But the world in which The Line of Beauty wins the Booker prize is markedly different from the world where same-sex desire once needed to operate through codes and secret languages. Historically, camp can be understood as a gay response to, and method for coping with and critiquing, the straight culture that oppresses it. It is 'a survival mechanism, a form of queer resistance in a world where the systems surrounding gender and sexuality are rigidly policed' ${ }^{28}$ But mainstream gay culture, in its reliance on the fixing of an authentic identity, polices its own rigid systems which work to erase bisexuality. 
What I identify as bisexual camp therefore operates as a site of specifically bisexual resistance to this monosexist gay culture. According to Jonathan Dollimore, camp negotiates some of the lived contradictions of subordination, simultaneously refashioning as a weapon of attack an oppressive identity inherited as subordination, and hollowing out dominant formations responsible for that identity in the first instance. $^{29}$

Bisexual camp therefore refashions the uncertainty, unresolvedness and hypersexualization of stereotypical constructions of bisexuality as weapons with which to attack contemporary gay discourse.

Perhaps inevitably, elements of Hollinghurst's previous novels fostered expectations which influenced the reception of The Stranger's Child. In particular, Tait observed that Hollinghurst seemed to have taken 'vows of chastity', and 'radically cut down on the sex, which is mostly shielded by soft focus or euphemism' in place of the explicit detail for which he is known. ${ }^{30}$ Take the first incident of sex in the novel, between Cecil and George, and the ellipsis through which it is (explicitly not) represented:

Cecil stopped and shrugged with pleasure, slipped off his jacket and hung it on the upraised claw [of the branch] above him. Then he turned and reached out his hands impatiently.

'That was very good', muttered Cecil, already standing up - then walking off for a few paces as he roughly straightened his clothes. .... He had a way of distancing himself at once, and seemed almost to counter the bleak little minute of irrational sadness by pretending that nothing had happened. (SC 78) 
After seventy-seven apparently chaste pages, the sex for which Cecil (and the reader) waits 'impatiently' is consigned to the blank space of a paragraph break and followed by an abrupt 'distancing'. In this way Hollinghurst plays with the expectation of explicit sex and overtly refuses to deliver it. But just like Cecil, he is only pretending that nothing has happened. To perceive this as chastity misreads what happens to the sex: it hasn't been removed, it has been dissolved into the rest of the text at the level of language such that the entire work is built upon a sexualized textuality that simultaneously withholds and indulges in it. Mendelsohn thinks that 'there is something tame' about this novel and that 'by the time you reach the last of its ... pages, you wonder whether a certain vital organ is missing'; for him the book comes to be defined by 'an absent penis'. ${ }^{31}$ This particular omission is announced when Paul Bryant looks at pictures by the bisexual artist Revel Ralph (who feels 'there is room in the world for more than one kind of beauty' (SC 141)) and notices a set of drawings

of a naked young man, ... everything about him wonderfully brought out, except his cock and balls which were consigned to the imagination by a swoop of the pencil, ostentatiously discreet, pretending it wasn't the point. (510)

Just like the genitals in these drawings, the sex has happened and is the point. Like Revel and Cecil, Hollinghurst is only pretending otherwise. Bisexuality, as Michael du Plessis notes, 'seems to lend itself to exaggeration - all or nothing; everyone is bisexual or no one is' ${ }^{32}$ This can be a further way in which bisexuality is delegitimized as a distinct identity experience or perspective (if everyone is bisexual then it loses any specificity, becoming synonymous with all sexuality; if no one is then it doesn't exist): here 'all or nothing' is repurposed through the text's representations of sex as all and nothing, everywhere and nowhere. Commonly, bisexuality is either rendered invisible (rewritten as gay, queer or immature) or else hypersexualized (visible only through promiscuity) ${ }^{33}$ the unrepresented 
sex in The Stranger's Child - which is then made conspicuous by its absence -_parodies both of these mechanisms. Eric Banks suggests that 'there's a primness to the sex here that feels ironically shocking in its blatant modesty'; ${ }^{34}$ it is in the ironic shock of Hollinghurst's ostentatious discretion that we encounter bisexual camp.

As the characters' lives are shaped by Cecil's absence, so the text becomes sexualized by the apparent absence of explicit sex; sex is found instead in near-constant innuendo. In one scene Daphne (aged 26) and the designer Eva Riley are in the garden:

'Can I tempt you?' said Eva ... . The nacreous curve of her cigarette case gleamed like treasure in the moonlight. 'Oh . . ! hmm ... well, all right ...'

Up flashed the oily flame of her lighter. 'I like to see you smoking', said Eva, as the tobacco crackled and glowed.

'I'm starting to like it myself,' said Daphne. ...

[Eva] slid her arm companionably round Daphne's waist.

'Let's try not to fall into the fishpond,' Daphne said, moving slightly apart.

'I wish you'd let me make you something lovely,' said Eva ... [and she] snuggled against her again cajolingly. . . . 'I wish you'd let me make you happy.'

Daphne said ... 'I'm really rather cold, I'm most frightfully sorry.' She jerked herself away, dropping her cigarette on the path and stamping on it. (SC 214-15)

Describing this to Revel a few moments later Daphne declares: 'I'm absolutely certain she was making love to me' (218). Daphne's interpretation indicates the way the absent sex permeates the rest of the text: the act of sex becomes an act of language (as indeed the more explicit sex of Hollinghurst's early writing often was). The novel repeatedly foregrounds coding and innuendo: Paul for instance ponders the real meaning in Daphne's memoir 'of 
Cecil preparing for a "mighty thrust"' (469) as well as 'the matter of Cecil's massive tip' given to servant Jonah (417). Indeed, at one stage 'it seemed Cecil had already become' a ‘codeword' for sexual encounters between Paul and lover Peter Rowe (340). By repeatedly announcing the ways in which language stands in for conspicuously absent sex, the text actually enables sex to be found almost everywhere throughout it. Being less explicit than Hollinghurst's other novels does not make it less sexual; indeed, its bisexual camp effect makes the ostensible absence of sex outrageously sexualized.

The cigarettes in the passage above are an obvious innuendo that has been set up in the opening section (sometimes a cigarette is not just a cigarette). Daphne, aged 16, goes into the garden in the dark, looking for Cecil and George; near the hammock she detects 'the gentlemanly whiff of Cecil's cigar' and overhears them wondering whether George and Daphne's older brother Hubert is a 'womanizer' (32-3). This is their word for heterosexual, and so it situates what follows in the context of coded sexual language: Cecil 'pulled on his cigar' and Daphne sees 'the scarlet burn of its tip' as it twitches and fades (34). Daphne feels 'a simple urge to climb in with' the two men. 'She had shared the hammock with her mother, when she was smaller,' but now 'she was mindful of the hot cigar'.

The cigar tip, barely showing, dithered in the air like some dimly luminous bug and then glowed into life again, but now it was George's face that she saw in its faint devilish light. "Oh, I thought it was Cecil's cigar," she said simply.

George chortled in three quick huffs of smoke. And Cecil cleared his throat somehow supportively and appreciatively. "So it was," said George, in his most paradoxical tone. "I'm smoking Cecil's cigar too."

“Oh really..." said Daphne, not knowing what tone to give the words. "Well, I shouldn't let Mother find out." (34) 
This passage establishes the bisexual triangle between these characters. Daphne, in her relations with Cecil, is more than 'a transvestic stand-in, an improvised George'. ${ }^{35}$ That sort of reading, necessary to assert Cecil's gayness, sidelines those parts of the text where it is made clear that Cecil does have interest for Daphne, or for other women; those points for instance at which it is revealed that he does not share George's 'fastidious horror at the mere idea of a cunt' (72), and indeed 'would fuck anyone' (456). A reading that subordinates the relationship between Cecil and Daphne to a supposedly more authentic homosexual desire for George therefore recalls attempts to rewrite bisexuality as 'really gay'.

Reading this bisexually takes us closer to the kinds of ambivalent sexuality which are being represented here. It also points to the novel's preoccupation with time, memory and narrative, all of which are as conflicted as its relationship to bisexuality. Explaining the prevalence of bisexuality in the novel, Hollinghurst states that 'one of the ideas of the book is about the unknowability or uncategorisabilty of human behaviour, and I was rather tempted into those ambiguous sexual areas' ${ }^{36} \mathrm{He}$ explicitly links the unnamed bisexuality with the novel's broader engagement with unknowability: characters' attempts to uncover truths, gay or otherwise, ultimately fail. He suggests that he had just become tired of that model ... where a book contains a secret which, when finally revealed, makes everything make sense. And it seems to me ... life's not like that .... I wanted to create uncertainty in the reader; the reader shares the uncertainty and ignorance of a lot of the characters themselves about what actually happened between people they knew quite well in the past. ... My subject was much more to do with not so much remembering as forgetting and the way so much about the past, about our own lives, is sort of irrevocably lost to us. ${ }^{37}$ 
This structural uncertainty aligns with the forgetting posited by Judith (Jack) Halberstam as integral to a queer project to think about 'an opportunity for a non-hetero-reproductive future'. ${ }^{38}$ Halberstam proposes 'a notion of queer forgetting within which the forgetful subject ... lives to create relationality anew in each moment and for each context and without a teleology'. ${ }^{39}$ I see similar possibilities in the ways in which The Stranger's Child imbricates narratives of sexuality, identity and literary tradition and repeatedly stages their failures.

'One's own life doesn't naturally have a shape', Hollinghurst has said in interview, 'one is constantly imposing a shape on it; constructing the narrative' ${ }^{40}$ The Stranger's Child, structured around unknowable gaps in time, exposes the limitations of these narratives and our reliance on their continuity by frustrating our desire to see how characters have arrived at each position. He explains that he 'loved the idea of leaving the characters at one point and then joining them 10, 15 years later without any real explanation; making the reader work out what's happened' ${ }^{41}$ Hollinghurst excises lines of continuity and fills in gaps only through the explicitly fallible and contradictory memories (or rather, forgetting) of those characters. What 'the reader is ultimately presented with', according to Elsa Cavalié, 'is a distinctly postmodernist mosaic of non-congruent portraits and texts, which simultaneously denounces the quest for an irrevocable and fictitious past while enhancing [their] fascination for it' ${ }^{42}$ These discontinuities expose and frustrate the desire for congruence and the desire for fulfilment through resolution.

In its very early stages The Stranger's Child was to be a series of short stories. ${ }^{43}$ The idea that the different sections of the novel are separate books, with different archives of literary influences, persists in their failure to fully and finally cohere. This facilitates a form of forgetting that defers and frustrates all 'attempts at finality or wholeness' and thus 'withholds fulfilment'. ${ }^{44}$ The withholding of both sexual and narrative fulfilment again converges in Cecil, The Stranger's Child's absent centre. The novel opens with a delayed 
arrival: Daphne, in the hammock, excitedly awaits Cecil and George, but Cecil 'must have missed his train, or at least his connection' (SC 3). Their eventual arrival becomes apparent when she hears 'an unfamiliar voice, with an edge to it, and then George's laugh. ... She couldn't really hear what they were saying, but she was disconcerted by Cecil's voice' (4). Remembering that 'edging' is a term for the sexual practice of intentionally delaying orgasm, Cecil's disconcerting voice then references the refusal to climax or resolve that is present in the broader structure of this narrative which has dissolved bi-sex into its language. The entire narrative becomes analogous to the holding plateau before orgasm: focussed not on the one climactic arrival but on the extended experience. The (non)orgasmic structure of the narrative seems to have been felt by Hollinghurst himself: 'Normally, I do have a brief but acute sort of depression when I finish a book ... but I was so desperate to get this thing off that I seem to have escaped that'. ${ }^{45}$ Perhaps he escaped his usual come-down - 'that bleak little minute of irrational sadness' (SC 78) - after a novel by constructing one which never 'gets off' at all but comes to embrace this frustration as the necessary failure of life and literature to cohere with finality, to split into all or nothing, this or that. Instead, The Stranger's Child has it both ways.

\footnotetext{
${ }^{1}$ Stephen Moss, 'Alan Hollinghurst: Sex on the Brain', Guardian 18 June 2011 <http://www.theguardian.com/books/2011/jun/18/alan-hollinghurst-interview> [accessed 8 August 2015].

${ }^{2}$ Kenji Yoshino, 'The Epistemic Contract of Bisexual Erasure', Stanford Law Review 52.2 (2000) 353-456.

${ }^{3}$ Robyn Ochs, 'Why We Need to "Get Bi”", Journal of Bisexuality 11.2-3 (2011) 171-75: 172.
} 
${ }^{4}$ Phoebe Davidson, "“Her Libido Had Flowed in Two Currents": Representations of Bisexuality in Psychoanalytic Case Studies' in The Bisexual Imaginary: Representation, Identity, and Desire, ed. Bi Academic Intervention (London: Cassell, 1997) 58-72: 64.

${ }^{5}$ Marjorie Garber, Vice Versa: Bisexuality and the Eroticism of Everyday Life (New York: Simon \& Schuster, 1995) 343.

${ }^{6}$ Esther Saxey, Homoplot (New York: Lang, 2008) 10.

${ }^{7}$ Ibid. 130.

${ }^{8}$ Esther Saxey, 'Desire without Closure in Jaime Hernandez' Love and Rockets', ImageTexT 3.1 (2006) < http://www.english.ufl.edu/imagetext/archives/v3_1/saxey/> [accessed 8 August 2015].

${ }^{9}$ Clare Hemmings, Bisexual Spaces: A Geography of Sexuality and Gender (New York: Routledge, 2002) 4.

${ }^{10}$ David Halperin, 'Thirteen Ways of Looking at a Bisexual', Journal of Bisexuality 9.3-4 (2009) 451-455: 454.

${ }^{11}$ Georges Letissier, 'Alan Hollinghurst/Ronald Firbank: Camp Filiation as an Aesthetic of the Outrageous', Études britanniques contemporaines 45 (2013) <http://ebc.revues.org/742> [accessed 8 August 2015].

${ }^{12}$ Andy Medhurst, 'Batman, Deviance and Camp' in The Many Lives of the Batman, ed. Roberta E. Pearson and William Uricchio (London: BFI, 1991) 149-63: 154.

${ }^{13}$ Andy Medhurst, 'Camp' in Lesbian and Gay Studies: A Critical Introduction,ed. Andy Medhurst and Sally Munt (London and Washington: Cassell, 1997) 274-93: 276.

${ }^{14}$ Medhurst, 'Batman, Deviance and Camp' 155.

${ }^{15}$ Fabio Cleto, 'Introduction: Queering the Camp' in Camp: Queer Aesthetics and the Performing Subject-A Reader, ed. Fabio Cleto (Edinburgh: Edinburgh University Press, 1999) 1-42: 5. 
${ }^{16}$ Ibid. 2-3.

${ }^{17}$ Ibid. 2.

18 Halperin, 'Thirteen Ways of Looking at a Bisexual' 451.

${ }^{19}$ Daniel Mendelsohn, 'In Gay and Crumbling England', New York Review of Books 10

November 2011 < http://www.nybooks.com/articles/archives/2011/nov/10/gay-and-

crumbling-england/> [accessed 8 August 2015]

${ }^{20}$ Marcin Sroczynski, 'The Stranger's Child: Alan Hollinghurst's Subversive Englishness', Acta Philologica 43 (2013) 77-86: 82.

${ }^{21}$ Mendelsohn, 'In Gay and Crumbling England'.

22 James Wood, 'Sons and Lovers', New Yorker 10 October 2011

<http://www.newyorker.com/magazine/2011/10/17/sons-and-lovers-james-wood $>$.[accessed 8 August 2015].

${ }^{23}$ Shiri Eisner, Bi: Notes for a Bisexual Revolution (Berkeley: Seal Press, 2013) 39.

${ }^{24}$ Theo Tait, 'The Stranger's Child by Alan Hollinghurst - Review', Guardian 17 June 2011

< http://www.theguardian.com/books/2011/jun/17/strangers-child-alan-hollinghurst-review $>$

[accessed 8 August 2015].

${ }^{25}$ Moss, 'Alan Hollinghurst'.

${ }^{26}$ Alice O’Keeffe, ‘Alan Hollinghurst, Bookseller 28 July 2011

〈http://www.thebookseller.com/profile/alan-hollinghurst> [accesed 8 August 2015].

${ }^{27}$ Scarlett Baron, 'An Interview with Alan Hollinghurst', Oxonian Review 4 June 2012

<http://www.oxonianreview.org/wp/an-interview-with-alan-hollinghurst-draft/> [accessed 6 August 2015].

${ }^{28}$ John M Wolf, 'Resurrecting Camp: Rethinking the Queer Sensibility', Communication, Culture \& Critique 6.2 (2013) 284-97: 286. 
${ }^{29}$ Jonathan Dollimore, 'Post/modern: On the Gay Sensibility, or the Pervert's Revenge on Authenticity' in Cleto ed., Camp, 221-36: 224.

${ }^{30}$ Tait, 'The Stranger's Child by Alan Hollinghurst - Review'.

${ }^{31}$ Mendelsohn, 'In Gay and Crumbling England'..

${ }^{32}$ Michael Du Plessis, 'Blatantly Bisexual; Or, Unthinking Queer Theory’ in Representing

Bisexualities: Subjects and Cultures of Fluid Desire, ed. Donald E. Hall and Maria

Pramaggiore (New York: New York UP, 1996) 19-54:19.

${ }^{33}$ Eisner, Bi 37-8.

${ }^{34}$ Eric Banks, 'Love Is a Battlefield', Bookforum Sept/Oct/Nov 2011

<http://www.bookforum.com/inprint/018_03/8281> [accesed 8 August 2015]

${ }^{35}$ Greg Graham-Smith, 'Sexuality and the Multicursal Maze in Alan Hollinghurst's The

Stranger's Child', Scrutiny2 17.2 (2012) 7-12: 10.

${ }^{36}$ Moss, 'Alan Hollinghurst'.

${ }^{37}$ Michael Cathcart, 'Alan Hollinghurst on The Stranger's Child' [video], Big Ideas <http://www.abc.net.au/tv/bigideas/stories/2012/04/16/3476838.htm> [accessed 8 August 2015].

${ }^{38}$ Judith Halberstam, The Queer Art of Failure (Durham NC: Duke University Press, 2011) 70.

${ }^{39}$ Ibid. 80.

${ }^{40}$ Angela Meyer, 'Pleasure, Memory, Decay, and The Stranger's Child: An Interview with Alan Hollinghurst', Literaryminded 11 April 2012 <http://literaryminded.com.au/2012/04/11/pleasure-memory-decay-and-the-strangers-childan-interview-with-alan-hollinghurst/> [accessed 8 August 2015]

${ }^{41}$ O'Keefe, 'Alan Hollinghurst'. 
${ }^{42}$ Elsa Cavalié, “"A book persisted as a coloured shadow at the edge of sight”: Englishness and Influence in Alan Hollinghurst's The Stranger's Child', Revue Interdisciplinaire "Textes \& contextes" $7(2012)<$ http://revuesshs.u-

bourgogne.fr/textes\&contextes/document.php?id=1765> [accessed 8 August 2015].

${ }^{43}$ Cathcart, 'Alan Hollinghurst on The Stranger's Child'.

${ }^{44}$ Graham-Smith, 'Sexuality and the Multicursal Maze in Alan Hollinghurst's The Stranger's Child' 8.

${ }^{45}$ Moss, 'Alan Hollinghurst'. 